\title{
Alternative Measures for IBS Management
}

\author{
Abdul Kader Mohiuddin* \\ Secretary \& Treasurer, Dr. M. Nasirullah Memorial Trust
}

*Corresponding author: Abdul Kader Mohiuddin, Secretary \& Treasurer, Dr. M. Nasirullah Memorial Trust, Tejgaon, Dhaka 1215, Bangladesh, E-mail: trymohi@gmail.com, Mobile: 01716477485.

To Cite This Article: Mohiuddin AK.. Alternative Measures for IBS Management. Am J Biomed Sci \& Res. 2019 - 5(5). AJBSR.MS.ID.000947. DOI: 10.34297/AJBSR.2019.05.000947.

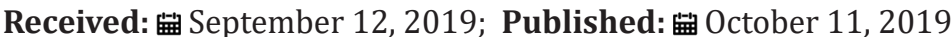

\begin{abstract}
About 30\% to $40 \%$ of adults claim to have frequent indigestion, and over 50 million visits are made annually to ambulatory care facilities for symptoms related to the digestive system. Irritable bowel syndrome (IBS) is present in patients with symptoms of chronic abdominal pain and altered bowel habits but no identifiable organic etiology. IBS has a prevalence of $1 \%$ to $20 \%$ worldwide, although up to $75 \%$ affected individuals never seek care. Diagnosing IBS can be challenging due to the nonspecific nature of symptoms, overlapping upper and lower abdominal symptoms, and the frequent presence of somatic and psychological comorbidities. Up to $80 \%$ of IBS patients identify food as a possible trigger for their symptoms, so they increasingly ask for dietary and behavioral counseling. Moderate-severe IBS is estimated to account for around $60 \%$ of all IBS cases and has been shown to impose a considerable burden on patients. It is estimated that IBS-C accounts for around $30 \%$ of IBS cases. The economic burden of IBS in the US is estimated at $\$ 28$ billion annually, a portion of these costs may be related to unnecessary and high-frequency tests, although few studies have assessed the factors underlying frequent tests and procedures among patients with IBS. 32\% of IBS-C patients suffer depression as their condition almost every day in the previous month. Sexual dysfunction is positively associated with perceived GI symptom severity and HRQoL

Keywords: Irritable Bowel Syndrome; Low-FODMAP; Cognitive Behavioral Therapy; Complementary and Alternative Medicine; Chinese Herbal Medicine; Brain-Gut Axis
\end{abstract}

Abbreviation: IBS: Irritable Bowel Syndrome; CBT-IE: Interoceptive Exposure-based CBT program; FODMAP: Fermentable Oligo-, Di-, Monosaccharides and Polyols; CAM: Complementary and Alternative Medicine

\section{Discussion}

Due to disappointing results with conventional IBS treatments, complementary and alternative medicines are becoming attractive options for many patients (Figure 1) [5-9]. Up to 50\% of patients declared that they used some form of CAM for their GI symptoms, ranging from biologically active compounds to mind-body interventions [10-18]. CAM alone and in conjunction with pharmacological treatments as an integrative approach to manage patients with IBS and imssssprove their QoL [12,19-22]. Prokinetics are not specific to IBS and increase gastrointestinal motility in general by acting via dopamine and 5-HT3 receptors as antagonists or 5-HT4 receptors as agonists [23-31]. Along with prokinetics, treatment revolves around the use of therapies which are not specifically approved/not truly effective for treating IBS-C, such as laxatives, antispasmodics, gastric relaxants, or central neuromodulators and bulking agents (e.g. dietary fibers) [32-40]. Novartis has agreed to continue to supply Zelnorm® (Tegaserod maleate) for use in emergency situations, due to an increased cardiovascular risk [41,42]. Alosetron hydrochloride (Lotronex), voluntarily withdrawn in November 2000 by GlaxoSmithKline, but put back on the market, is the only medication approved for the treatment of severe IBS-D in women who have inadequately responded to conventional therapy [43-47]. However, no studies have evaluated the efficacy of alosetron using the new FDA composite endpoint which requires improvement in both abdominal pain and diarrhea $[47,48]$. A mixture of dried powdered slippery elm bark, lactulose, oat bran, and licorice root significantly improved both bowel habit and IBS symptoms in patients with IBS-C [49]. More than 95\% of patients rated artichoke leaf extract as better than or at least equal to previous therapies administered for their symptoms, and the tolerability was very good [50]. Probiotics may be useful in the management of IBS; however, dose and specific bacterial strain are important [51]. Entericcoated peppermint oil is a safe and effective therapy for the relief of abdominal pain and global symptoms and in adults with IBS. Menthacarin, the primary component blocks $\mathrm{Ca} 2+$ channels and causing the relaxation of intestinal smooth muscle tissue [52-60]. STW 5 is a liquid formulation of nine herbs (Iberis amara totalis 
recens, Angelicae radix, Cardui mariae fructus, Chelidonii herba, Liquiritiae radix, Matricariae flos, Melissae folium, Carvi fructus and Menthae piperitae folium) used in clinical practice in Germany for more than 50 years, acts beneficially on abdominal symptom clusters as well as on individual GI symptoms in adults and children with efficacy, tolerability, reduced children school absenteeism [61-70]. Turmeric (Curcuma longa) or Java ginger (Curcuma xanthorrhiza) or curcumin, a biologically active phytochemical or combination with fennel oil was found to be beneficial, improved patient QoL (due to myorelaxant effect towards the intestinal muscle, involves not only the cholinergic receptors, but also L type Calcium channels) but not statistically significant in IBS symptoms (compared with placebo) [50,71-80]. Enzymes comprise the endocannabinoid system in intestinal pain and motility in IBS is also claimed [81] but no significant difference found with dronabinol/ nabilone (synthetic compounds containing cannabinoids found in the marijuana plant) [82-86]. Aloe Vera found to be improved QoL with insignificant/no severity symptom reduction in several studies [87-94] and studies show its carcinogenic potential in the colon [90,95-98], nephrotoxicity and hepatotoxicity [95,99-104] which surely demands very limited use unless necessary. Zingier officinale also showed limited potential in symptom management [105-108]. Mixture of Boswellia carterii, Zingiber officinale, and Achillea millefolium improved QoL in men but not in women [109]. Although, an earlier study with Mentha longifolia, Cyperus rotundus and Zingiber officinale combination showed significant improvements after 8-weeks of treatment [110]. CAM for IBS include hypnosis, acupuncture, cognitive behavior therapy, yoga, probiotics, meditation, and herbal medicine [12,19,50,111-113]. Yan et al. [114] \& Wu et al. [115] and few other studies reported efficiency and safety of acupuncture alone or combined with Moxibustion or other CHM in IBS [12,114-126]. Like zingiber officinale and Curcuma longa, Fumaria officinalis, Hypericum perforatum, Plantago psyllium and Carmint (Mentha spicata, Melissa officinalis, Coriandrum sativum) do not have significant efficacy or at least similar efficacy as placebo is also reported [50]. CHM like Sishen Wan, Ma Zi Ren Wan, CCH1 (patented, modified herb formula), Hemp seed pill, Jianpi Tiaogan Wenshen Recipe (JTWR), Chinese Medicine syndrome-differentiation therapy, Yun-chang capsule, plantain-senna granule (CPSG), Tongxie Yaofang (TXYF) Granule, Changjishu soft elastic capsule, Tongyouqing and many more showed potentials in IBS [127]. The emerging role of braingut therapies in IBS are visible. Cognitive behavioral therapy (CBT) and gut-directed hypnosis are the primary behavioral interventions that are introduced to patients with gastrointestinal conditions [128]. IBS involves dysregulation of the brain-gut axis and psychological processes play an important role in the development and maintenance of the disorder [129]. Gut-focused hypnotherapy was found to be effective in primary and secondary care [130133], but only small changes were found in intestinal microbiota composition [134]. CBT-IE for IBS includes exposure to abdominal sensations in addition to psychoeducation, self-monitoring, cognitive restructuring, attention training, and in vivo exposure, which are often used in traditional CBT [135]. Home-based version of CBT produced significant and sustained gastrointestinal symptom improvement for patients with IBS compared with education [136]. Both web/phone-delivered CBT and home/clinic-based CBT was found to be effective than usual treatment in refractory IBS, resulted in substantial and enduring relief of multiple symptoms [137,138]. Although significant for both outcomes, the statistical analysis revealed CBT interventions have a greater effect on alleviating IBS symptoms severity rather than on reducing psychological distress [139]. Emotional stress exacerbates IBS symptoms, and mind-body interventions may be beneficial. Exercise (yoga, walking/aerobic physical activity, Tai Ji, mountaineering, and Baduanjin qigong activity) is potentially a feasible and effective treatment for IBS patients [140]. Yoga improved sleep increased visceral sensitivity and reduced abdominal pain in teens [141], adolescents and young adults [142], women [143] and postmenopausal women [144]. Patients with irritable bowel syndrome might benefit from yoga and a low-FODMAP diet, as both groups showed a reduction in gastrointestinal symptoms [145]. Low-FODMAPs, ketogenic glutenfree diets are considered therapeutic [146-150]. However, there are gaps in implementation of the low FODMAP diet in clinical practice, as well as long-term safety and efficacy [151]. A low FODMAP diet is only recommended as a second line treatment guided by qualified clinicians with specialized training [152]. Dietary sources fibers include oats, psyllium, ispaghula, nuts and seeds, some fruit and vegetables and pectins. An increase in fiber has often been suggested as an initial treatment for IBS [153].

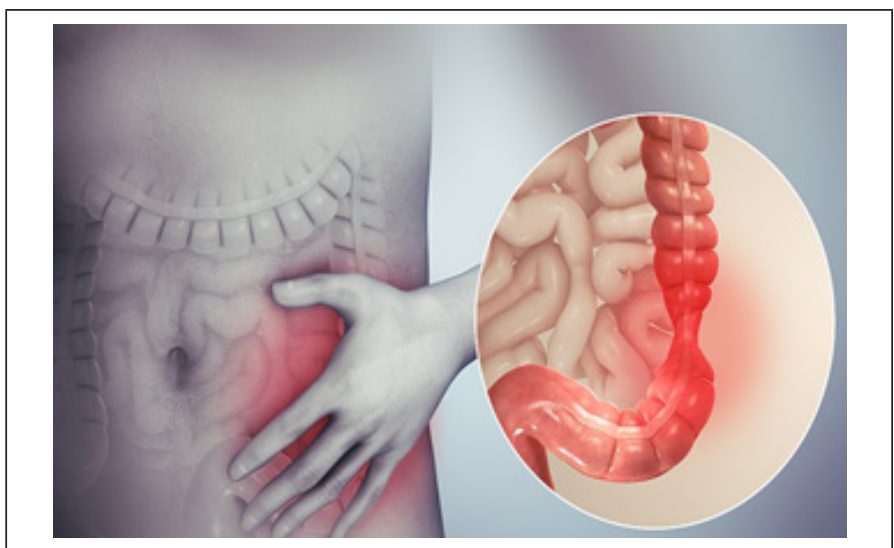

Figure 1: Irritable Bowel Syndrome [1-4]. IBS is a disease representative of FGIDs in which abdominal pain and discomfort associated with abnormal bowel movements chronically persist and recur. These symptoms are known to be related to lifestyle habits, such as meals and stress. It has been reported that $50 \%$ to $90 \%$ of patients have or had at some point one or more common psychiatric condition, including major depressive disorder, generalized anxiety disorder, social phobia, somatization disorder, or posttraumatic stress disorder. A survey by the Gastrointestinal Society in Canada showed that nearly $50 \%$ had missed work or school due to IBS symptoms. In the US, Canada, and Israel, IBS symptoms are 1.5 to 2 times more prevalent among women than men. Moreover, women are more likely to report abdominal pain and constipation whereas men are more likely to report diarrhea.

There is strong evidence to support three mechanisms of action: 
a) Augmentation of small intestinal fluid

b). Increased colonic fermentation

c). Immune modulation [154].

However, water-insoluble fiber does not improve IBS symptoms, consuming soluble fiber improves overall IBS symptoms [155].

\section{Acknowledgement}

I'm thankful to Dr. Elshazaly Saeed F.E.H. Elhassan, King Saud University, Saudi Arabia for his precious time to review my literature and for her thoughtful suggestions. I'm also grateful to seminar library of Faculty of Pharmacy, University of Dhaka and BANSDOC Library, Bangladesh for providing me books, journal and newsletters.

\section{References}

1. Okawa Y, Fukudo S, Sanada H (2019) Specific foods can reduce symptoms of irritable bowel syndrome and functional constipation: a review. Biopsychosoc Med 13: 10.

2. Abdul Rani R, Raja Ali RA, Lee YY (2016) Irritable bowel syndrome and inflammatory bowel disease overlap syndrome: pieces of the puzzle are falling into place. Intest Res 14(4): 297-304.

3. Mohiuddin AK (2019) Alternative Treatments for Minor GI Ailments. INNOVATIONS in pharmacy $10(3)$.

4. Patel N, Shackelford KS (2019) Irritable Syndrome Syndrome. StatPearls [Internet].

5. Rahimi R, Abdollahi M (2012) Herbal medicines for the management of irritable bowel syndrome: a comprehensive review. World J Gastroenterol 18(7): 589-600.

6. Wu JC (2010) Complementary and alternative medicine modalities for the treatment of irritable bowel syndrome: facts or myths? Gastroenterol Hepatol (NY) 6(11): 705-711.

7. Adeyemo MA, Chang L (2008) New treatments for irritable bowel syndrome in women. Women's Health (Lond) 4(6): 605-622.

8. Peyton L, Greene J (2014) Irritable bowel syndrome: current and emerging treatment options. PT 39(8): 567-578.

9. Anastasi JK, Capili B, Chang M (2013) Managing irritable bowel syndrome. Am J Nurs 113(7): 42-52.

10. Larussa T, Rossi M, Suraci E, Marasco R, Imeneo M, et al. (2019) Use of Complementary and Alternative Medicine by Patients with Irritable Bowel Syndrome According to the Roma IV Criteria: A Single-Center Italian Survey. Medicina (Kaunas) 13: 55(2).

11. Nguyen L (2018) Complementary and Alternative Medicine for the Management of Irritable Bowel Syndrome. Gastroenterol Hepatol (NY) 14(9): 536-538.

12. Shen YH, Nahas R (2009) Complementary and alternative medicine for treatment of irritable bowel syndrome. Can Fam Physician 55(2): 143 148.

13. Chiarioni G, Pesce M, Fantin A, Sarnelli G (2018) Complementary and alternative treatment in functional dyspepsia. United European Gastroenterol J 6(1): 5-12.

14. Tabish SA (2008) Complementary and Alternative Healthcare: Is it Evidence-based? Int J Health Sci (Qassim) 2(1): V-IX.

15. Callahan LF, Wiley-Exley EK, Mielenz TJ, Brady TJ, Xiao C et al. (2009) Use of complementary and alternative medicine among patients with arthritis. Prev Chronic Dis 6(2): A44.

16. Goldenberg JZ, Steel A, Day A, Yap C, Bradley R, et al. (2018) Naturopathic approaches to irritable bowel syndrome: protocol for a prospective observational study in academic teaching clinics. Integr Med Res 7(3): 279-286.

17. Lail G, Luck N, Tasneem AA, Rai A, Laeeq SM, et al. (2016) The usage of complementary and alternative medicine in gastrointestinal patients visiting the outpatient's department of a large tertiary care center-views from Pakistan. Pan Afr Med J 24: 247.

18. Brien SB, Bishop FL, Riggs K, Stevenson D, Freire V, et al. (2011) Integrated medicine in the management of chronic illness: a qualitative study. Br J Gen Pract 61(583): e89-96.

19. Grundmann O, Yoon SL (2014) Complementary and alternative medicines in irritable bowel syndrome: an integrative view. World J Gastroenterol 20(2): 346-362.

20. Harris LR, Roberts L (2008) Treatments for irritable bowel syndrome: patients' attitudes and acceptability. BMC Complement Altern Med 8: 65.

21. Hussain Z, Quigley EM (2006) Systematic review: Complementary and alternative medicine in the irritable bowel syndrome. Aliment Pharmacol Ther 23(4): 465-471.

22. Usher, Lee, Pauline Fox, Caroline Lafarge, Kathryn Mitchell (2013) "Factors Associated with Complementary and Alternative Medicine Use in Irritable Bowel Syndrome: A Literature Review." Psychology, Community \& Health pp. 346-361.

23. Jadallah KA, Kullab SM, Sanders DS (2014) Constipation-predominant irritable bowel syndrome: a review of current and emerging drug therapies. World J Gastroenterol 20(27): 8898-8909.

24. Sinagra E, Morreale GC, Mohammadian G, Fusco G, Guarnotta V, et al. (2017) New therapeutic perspectives in irritable bowel syndrome: Targeting low-grade inflammation, immuno-neuroendocrine axis, motility, secretion and beyond. World J Gastroenterol 23(36): 65936627.

25. Lang L (2008) The Food and Drug Administration approves lubiprostone for irritable bowel syndrome with constipation. Gastroenterology 135(1): 7.

26. Sweetser S, Busciglio IA, Camilleri M, Bharucha AE, Szarka LA, Papathanasopoulos A, et al. (2009) Effect of a chloride channel activator, lubiprostone, on colonic sensory and motor functions in healthy subjects. Am J Physiol Gastrointest Liver Physiol 296(2): G295-301.

27. Moayyedi P, Mearin F, Azpiroz F, Andresen V, Barbara G, et al. (2017) Irritable bowel syndrome diagnosis and management: A simplified algorithm for clinical practice. United European Gastroenterol J 5(6): 773-788.

28. Tameez Ud Din A, Khan AH, Bajwa H, Maqsood MH, Malik MN (2019) Clinical Efficacy and Safety Profile of Prucalopride in Chronic Idiopathic Constipation. Cureus 11(4): e4382.

29. Stefano Evangelista (2012) "Benefits from Long-Term Treatment in Irritable Bowel Syndrome," Gastroenterology Research and Practice Pp.

30. Quigley EMM (2017) Prokinetics in the Management of Functional Gastrointestinal Disorders. Curr Gastroenterol Rep 19(10): 53.

31. Bellini M, Gambaccini D, Stasi C, Urbano MT, Marchi S, Usai-Satta P (2014) Irritable bowel syndrome: a disease still searching for pathogenesis, diagnosis and therapy. World J Gastroenterol 20(27): 8807-8820.

32. Tack J, Stanghellini V, Mearin F, Yiannakou Y, Layer P, Coffin B, et al. (2019) Economic burden of moderate to severe irritable bowel syndrome with constipation in six European countries. BMC Gastroenterol 19(1): 69.

33. Wang XJ, Camilleri M (2019) Personalized medicine in functional gastrointestinal disorders: Understanding pathogenesis to increase diagnostic and treatment efficacy. World J Gastroenterol 25(10):11851196.

34. Talley NJ (2003) Evaluation of drug treatment in irritable bowel syndrome. Br J Clin Pharmacol 56(4): 362-369.

35. Occhipinti K, Smith JW (2012) Irritable bowel syndrome: a review and update. Clin Colon Rectal Surg 25(1): 46-52. 
36. Furnari M, de Bortoli N, Martinucci I, Bodini G, Revelli M, et al. (2015) Optimal management of constipation associated with irritable bowel syndrome. Ther Clin Risk Manag 11: 691-703.

37. Annaházi A, Róka R, Rosztóczy A, Wittmann T (2014) Role of antispasmodics in the treatment of irritable bowel syndrome. World J Gastroenterol 20(20): 6031-6043.

38. Reina J, Smith JW (2005) Medical treatment of irritable bowel syndrome. Clin Colon Rectal Surg 18(2):102-108.

39. Hammerle CW, Surawicz CM (2008) Updates on treatment of irritable bowel syndrome. World J Gastroenterol 14(17): 2639-2649.

40. Basnayake C (2018) Treatment of irritable bowel syndrome. Aust Prescr 41(5): 145-149.

41. (2018) Zelnorm (tegaserod maleate) Information. US FDA Admin.

42. (2007) Key Point. Tegaserod withdrawn from US market. APhA Drug Info Online Web.

43. WHO Web. Alosetron - withdrawn severe adverse reactions.

44. Charatan F (2002) FDA advisory panels recommend Lotronex be put back on market. BMJ 324(7345): 1053.

45. Moynihan R (2002) Alosetron: a case study in regulatory capture, or a victory for patients' rights? BMJ 325(7364): 592-595.

46. Lucak SL (2010) Optimizing outcomes with alosetron hydrochloride in severe diarrhea-predominant irritable bowel syndrome. Therap Adv Gastroenterol 3(3): 165-172.

47. Lacy BE, Nicandro JP, Chuang E, Earnest DL (2018) Alosetron use in clinical practice: significant improvement in irritable bowel syndrome symptoms evaluated using the US Food and Drug Administration composite endpoint. Therap Adv Gastroenterol 11: 1756284818771674.

48. US Department of Health and Human Services Food and Drug Administration Center for Drug Evaluation and Research (CDER). Guidance for industry: irritable bowel syndrome-clinical evaluation of drugs for treatment.

49. Hawrelak JA, Myers SP (2010) Effects of two natural medicine formulations on irritable bowel syndrome symptoms: a pilot study. J Altern Complement Med 16(10): 1065-1071.

50. Bahrami HR, Hamedi S, Salari R, Noras M (2016) Herbal Medicines for the Management of Irritable Bowel Syndrome: A Systematic Review. Electron Physician 8(8): 2719-2725.

51. National Collaborating Centre for Nursing and Supportive Care (UK) (2008) Irritable Bowel Syndrome in Adults: Diagnosis and Management of Irritable Bowel Syndrome in Primary Care [Internet]. London: Royal College of Nursing (UK), (NICE Clinical Guidelines (61)7.

52. Alammar N, Wang L, Saberi B, Nanavati J, Holtmann G, et al. (2019) The impact of peppermint oil on the irritable bowel syndrome: a metaanalysis of the pooled clinical data. BMC Complement Altern Med 19(1): 21.

53. Khanna R, MacDonald JK, Levesque BG (2014) Peppermint oil for the treatment of irritable bowel syndrome: a systematic review and metaanalysis. J Clin Gastroenterol 48(6): 505-512.

54. Cash BD, Epstein MS, Shah SM (2016) A Novel Delivery System of Peppermint Oil Is an Effective Therapy for Irritable Bowel Syndrome Symptoms. Dig Dis Sci 61(2): 560-571

55. Grigoleit HG, Grigoleit P (2005) Peppermint oil in irritable bowe syndrome. Phytomedicine 12(8): 601-606.

56. Merat S, Khalili S, Mostajabi P, Ghorbani A, Ansari R, et al. (2010) The effect of enteric-coated, delayed-release peppermint oil on irritable bowel syndrome. Dig Dis Sci 55(5): 1385-1390.

57. Cappello G, Spezzaferro M, Grossi L, Manzoli L, Marzio L (2007) Peppermint oil (Mintoil) in the treatment of irritable bowel syndrome: a prospective double-blind placebo-controlled randomized trial. Dig Liver Dis 39(6): 530-536.
58. Wall GC, Bryant GA, Bottenberg MM, Maki ED, Miesner AR (2014) Irritable bowel syndrome: a concise review of current treatment concepts. World J Gastroenterol 20(27): 8796-8806.

59. Chumpitazi BP, Kearns GL, Shulman RJ (2018) The physiological effects and safety of peppermint oil and its efficacy in irritable bowel syndrome and other functional disorders. Aliment Pharmacol Ther 47(6): 738-752.

60. Fifi AC, Axelrod CH, Chakraborty P, Saps M (2018) Herbs and Spices in the Treatment of Functional Gastrointestinal Disorders: A Review of Clinical Trials. Nutrients 10(11): E1715.

61. Gundermann KJ, Vinson B (2004) Die funktionelle Dyspepsie bei Kindern-eine retrospektive Studie mit einem Phytopharmakon. Päd 10: $1-6$.

62. Malfertheiner P (2017) STW 5 (Iberogast) Therapy in Gastrointestinal Functional Disorders. Dig Dis 35(1): 25-29.

63. Ottillinger B, Storr M, Malfertheiner P, Allescher HD (2013) STW 5 (Iberogast $($ )-a safe and effective standard in the treatment of functional gastrointestinal disorders. Wien Med Wochenschr 163(3-4): 65-72.

64. Lapina TL, Trukhmanov AS (2017) Herbal Preparation STW 5 for Functional Gastrointestinal Disorders: Clinical Experience in Everyday Practice. Dig Dis 35(1): 30-35.

65. Allescher HD, Abdel-Aziz H (2017) Mechanism of Action of STW 5 in Functional Dyspepsia and IBS: The Origin of Multi-Target. Dig Dis 35(1):18-24.

66. Raedsch R, Vinson B, Ottillinger B, Holtmann G (2018) Early onset of efficacy in patients with functional and motility-related gastrointestinal disorders: A noninterventional study with Iberogast ${ }^{\circledR}$. Wien Med Wochenschr 168(3-4): 89-98.

67. Mearin F, Malfertheiner P (2017) Functional Gastrointestinal Disorders: Complex Treatments for Complex Pathophysiological Mechanisms. Dig Dis 35(1): 1-4.

68. Abdel-Aziz H, Kelber O, Lorkowski G, Storr M (2017) Evaluating the Multitarget Effects of Combinations through Multistep Clustering of Pharmacological Data: The Example of the Commercial Preparation Iberogast. Planta Med 83(14-15): 1130-1140.

69. Ochoa-Cortes F, Liñán-Rico A, Jacobson KA, Christofi FL (2014) Potential for developing purinergic drugs for gastrointestinal diseases. Inflamm Bowel Dis 20(7): 1259-1287.

70. Madisch A, Vinson BR, Abdel-Aziz H, Kelber O, Nieber K, et al. (2017) Modulation of gastrointestinal motility beyond metoclopramide and domperidone: Pharmacological and clinical evidence for phototherapy in functional gastrointestinal disorders. Wien Med Wochenschr 167(78): $160-168$

71. Ng QX, Soh AYS, Loke W, Venkatanarayanan N, Lim DY, et al. (2018) A Meta-Analysis of the Clinical Use of Curcumin for Irritable Bowel Syndrome (IBS). J Clin Med 7(10): E298.

72. Bundy R, Walker AF, Middleton RW, Booth J (2004) Turmeric extract may improve irritable bowel syndrome symptomology in otherwise healthy adults: a pilot study. J Altern Complement Med 10(6): 1015-1018.

73. Dulbecco P, Savarino V (2013) Therapeutic potential of curcumin in digestive diseases. World J Gastroenterol 19(48): 9256-9270.

74. Kandola A (2018) Turmeric for IBS: Does it work? Medical News Today.

75. Micucci M, Aldini R, Cevenini M, Colliva C, Spinozzi S, et al. (2013) Curcuma longa L. as a therapeutic agent in intestinal motility disorders. 2: Safety profile in mouse. PLoS One 8(11): e80925.

76. Khan I, Samson SE, Grover AK (2017) Antioxidant Supplements and Gastrointestinal Diseases: A Critical Appraisal. Med Princ Pract 26(3): 201-217.

77. Di Ciaula A, Portincasa P, Maes N, Albert A (2018) Efficacy of biooptimized extracts of turmeric and essential fennel oil on the quality of life in patients with irritable bowel syndrome. Ann Gastroenterol 31(6): 685-691. 
78. Portincasa P, Bonfrate L, de Bari O, Lembo A, Ballou S (2017) Irritable bowel syndrome and diet. Gastroenterol Rep (Oxf) 5(1): 11-19.

79. Portincasa P, Bonfrate L, Scribano ML, Kohn A, Caporaso N, et al. (2016) Curcumin and Fennel Essential Oil Improve Symptoms and Quality of Life in Patients with Irritable Bowel Syndrome. J Gastrointestin Liver Dis 25(2): 151-157.

80. Lakhan SE, Ford CT, Tepper D (2015) Zingiberaceae extracts for pain: a systematic review and meta-analysis. Nutr J 14: 50.

81. Russo EB (2008) Cannabinoids in the management of difficult to treat pain. Ther Clin Risk Manag 4(1): 245-259.

82. Wong BS, Camilleri M, Eckert D, Carlson P, Ryks M, et al. (2012) Randomized pharmacodynamic and pharmacogenetic trial of dronabinol effects on colon transit in irritable bowel syndrome-diarrhea. Neurogastroenterol Motil 24(4): 358-e169.

83. Klooker TK, Leliefeld KE, Van Den Wijngaard RM, Boeckxstaens GE (2011) The cannabinoid receptor agonist delta-9-tetrahydrocannabinol does not affect visceral sensitivity to rectal distension in healthy volunteers and IBS patients. Neurogastroenterol Motil 23(1): 30-35.

84. Bokic T, Storr M, Schicho R (2015) Potential Causes and Present Pharmacotherapy of Irritable Bowel Syndrome: An Overview. Pharmacology 96(1-2): 76-85.

85. Fraguas-Sánchez AI, Torres-Suárez AI (2018) Medical Use of Cannabinoids. Drugs 78(16): 1665-1703.

86. Halawi H, Camilleri M (2017) Pharmacogenetics and the treatment of functional gastrointestinal disorders. Pharmacogenomics 18(11): 10851094.

87. Davis K, Philpott S, Kumar D, Mendall M (2006) Randomised doubleblind placebo-controlled trial of aloe vera for irritable bowel syndrome. Int J Clin Pract 60(9): 1080-1086.

88. Hutchings HA, Wareham K, Baxter JN, Atherton P, Kingham JG, et al (2011) A Randomised, Cross-Over, Placebo-Controlled Study of Aloe vera in Patients with Irritable Bowel Syndrome: Effects on Patient Quality of Life. ISRN Gastroenterol 2011: 206103.

89. Størsrud S, Pontén I, Simrén M (2015) A Pilot Study of the Effect of Aloe barbadensis Mill. Extract (AVH200®) in Patients with Irritable Bowel Syndrome: a Randomized, Double-Blind, Placebo-Controlled Study. J Gastrointestin Liver Dis 24(3): 275-280.

90. Hong SW, Chun J, Park S, Lee HJ, Im JP, et al. (2018) Aloe vera Is Effective and Safe in Short-term Treatment of Irritable Bowel Syndrome: A Systematic Review and Meta-analysis. J Neurogastroenterol Motil 24(4): 528-535.

91. Khedmat H, Karbasi A, Amini M, Aghaei A, Taheri S (2013) Aloe vera in treatment of refractory irritable bowel syndrome: Trial on Iranian patients. J Res Med Sci 18(8): 732.

92. Kandola A (2018) Is Aloe vera juice good for IBS? MedicalNewsToday.

93. Foster M, Hunter D, Samman S (2011) Evaluation of the Nutritional and Metabolic Effects of Aloe vera. In: Benzie IFF, Wachtel-Galor S, editors. Herbal Medicine: Biomolecular and Clinical Aspects. $2^{\text {nd }}$ edn. Boca Raton (FL): CRC Press/Taylor \& Francis.

94. Lacy BE, Weiser K, De Lee R (2009) The treatment of irritable bowel syndrome. Therap Adv Gastroenterol. 2(4): 221-238.

95. Guo X, Mei N (2016) Aloe vera: A review of toxicity and adverse clinical effects. J Environ Sci Health C Environ Carcinog Ecotoxicol Rev 34(2): 77-96.

96. Boudreau MD, Mellick PW, Olson GR, Felton RP, Thorn BT, et al. (2013) Clear evidence of carcinogenic activity by a whole-leaf extract of Aloe barbadensis miller (aloe vera) in F344/N rats. Toxicol Sci 131(1): 26-39.

97. Boudreau MD, Beland FA, Nichols JA, Pogribna M (2013) Toxicology and carcinogenesis studies of a nondeodorized [corrected] whole leaf extract of Aloe barbadensis Miller (Aloe vera) in F344/N rats and B6C3F1 mice (drinking water study). Natl Toxicol Program Tech Rep Ser (577): 1-266.
98. Boudreau MD, Olson GR, Tryndyak VP, Bryant MS, Felton RP, et al. (2017) From the Cover: Aloin, a Component of the Aloe Vera Plant Leaf, Induces Pathological Changes and Modulates the Composition of Microbiota in the Large Intestines of F344/N Male Rats. Toxicol Sci 158(2): 302-318.

99. Yang HN, Kim DJ, Kim YM, Kim BH, Sohn KM, et al. (2010) Aloe-induced toxic hepatitis. J Korean Med Sci 25(3): 492-495.

100. Bottenberg MM, Wall GC, Harvey RL, Habib S (2007) Oral aloe verainduced hepatitis. Ann Pharmacother 41(10): 1740-1743.

101. Lee J, Lee MS, Nam KW (2014) Acute toxic hepatitis caused by an aloe vera preparation in a young patient: a case report with a literature review. Korean J Gastroenterol 64(1): 54-58.

102. Curciarello J, De Ortúzar S, Borzi S, Bosia D (2008) Severe acute hepatitis associated with intake of Aloe vera tea. Gastroenterol Hepatol 31(7): 436-438.

103. Frenzel C, Teschke R (2016) Herbal Hepatotoxicity: Clinical Characteristics and Listing Compilation. Int J Mol Sci 17(5): E588.

104. Saka W, Akhigbe R, Popoola O, Oyekunle O (2012) Changes in Serum Electrolytes, Urea, and Creatinine in Aloe Vera-treated Rats. J Young Pharm 4(2): 78-81.

105. van Tilburg MA, Palsson OS, Ringel Y, Whitehead WE (2014) Is ginger effective for the treatment of irritable bowel syndrome? A double blind randomized controlled pilot trial. Complement Ther Med 22(1): 17-20.

106. Yuki M, Komazawa Y, Kobayashi Y, Kusunoki M, Takahashi Y, et al. (2015) Effects of Daikenchuto on Abdominal Bloating Accompanied by Chronic Constipation: A Prospective, Single-Center Randomized Open Trial. Curr Ther Res Clin Exp 77: 58-62.

107. Hu ML, Rayner CK, Wu KL, Chuah SK, Tai WC, et al. (2011) Effect of ginger on gastric motility and symptoms of functional dyspepsia. World J Gastroenterol 17(1): 105-110.

108. Nikkhah Bodagh M, Maleki I, Hekmatdoost A (2018) Ginger in gastrointestinal disorders: A systematic review of clinical trials. Food Sci Nutr 7(1): 96-108.

109. Kazemian A, Toghiani A, Shafiei K, Afshar H, Rafiei R, et al. (2018) Evaluating the efficacy of mixture of Boswellia carterii, Zingiber officinale, and Achillea millefolium on severity of symptoms, anxiety, and depression in irritable bowel syndrome patients. J Res Med Sci 22: 120.

110. Sahib AS (2013) Treatment of irritable bowel syndrome using a selected herbal combination of Iraqi folk medicines. J Ethnopharmacol 148(3): 1008-1012.

111. Lichtenstein GR (2018) Brain-Gut Therapies and Irritable Bowel Syndrome. Gastroenterol Hepatol (NY) 14(7): 399.

112. Lin SC, Cheifetz AS (2018) The Use of Complementary and Alternative Medicine in Patients with Inflammatory Bowel Disease. Gastroenterol Hepatol (NY) 14(7): 415-425.

113. Moayyedi P, Andrews CN, MacQueen G, Korownyk C, Marsiglio M, et al. (2019) Canadian Association of Gastroenterology Clinical Practice Guideline for the Management of Irritable Bowel Syndrome (IBS). J Can Assoc Gastroenterol 2(1): 6-29.

114. Yan J, Miao ZW, Lu J, Ge F, Yu LH, et al. (2019) Acupuncture plus Chinese Herbal Medicine for Irritable Bowel Syndrome with Diarrhea: A Systematic Review and Meta-Analysis. Evid Based Complement Alternat Med 2019: 7680963.

115. Wu IXY, Wong CHL, Ho RST, Cheung WKW, Ford AC, et al. (2019) Acupuncture and related therapies for treating irritable bowel syndrome: overview of systematic reviews and network meta-analysis. Therap Adv Gastroenterol 12: 1756284818820438.

116. Manheimer E, Cheng K, Wieland LS, Min LS, Shen X, et al. (2012) Acupuncture for treatment of irritable bowel syndrome. Cochrane Database Syst Rev 16(5): CD005111. 
117. Chao GQ, Zhang S (2014) Effectiveness of acupuncture to treat irritable bowel syndrome: a meta-analysis. World J Gastroenterol 20(7): 18711877.

118. Lim B, Manheimer E, Lao L, Ziea E, Wisniewski J, Liu J, Berman B (2006) Acupuncture for treatment of irritable bowel syndrome. Cochrane Database Syst Rev 16(5): CD005111.

119. Li CY, Li SC (2015) Treatment of irritable bowel syndrome in China: a review. World J Gastroenterol 21(8): 2315-2322.

120. Ma XP, Hong J, An CP, Zhang D, Huang Y, Wu HG, et al. (2014) Acupuncture-moxibustion in treating irritable bowel syndrome: how does it work? World J Gastroenterol 20(20): 6044-6054.

121. Anastasi JK, Capili B (2012) The Treatment of ConstipationPredominant Irritable Bowel Syndrome with Acupuncture and Moxibustion: A Case Report. J Chin Med 99: 68-71.

122. Anastasi JK, Capili B, Chang M (2017) Development of Acupuncture and Moxibustion Protocol in a Clinical Trial for Irritable Bowel Syndrome. ] Acupunct Meridian Stud 10(1): 62-66.

123. Lin X, Liu X, Xu J, Cheng KK, Cao J, Liu T, et al. (2019) Metabolomics analysis of herb-partitioned moxibustion treatment on rats with diarrhea-predominant irritable bowel syndrome. Chin Med 14: 18.

124. Park JW, Lee BH, Lee H (2013) Moxibustion in the management of irritable bowel syndrome: systematic review and meta-analysis. BMC Complement Altern Med 13: 247.

125. Manheimer E, Wieland LS, Cheng K, Li SM, Shen X, Berman BM, et al. (2012) Acupuncture for irritable bowel syndrome: systematic review and meta-analysis. Am J Gastroenterol 107(6): 835-847.

126. Forbes A, Jackson S, Walter C, Quraishi S, Jacyna M, et al. (2005) Acupuncture for irritable bowel syndrome: a blinded placebocontrolled trial. World J Gastroenterol 11(26): 4040-4044.

127. Teschke R, Wolff A, Frenzel C, Eickhoff A, Schulze J (2015) Herbal traditional Chinese medicine and its evidence base in gastrointestinal disorders. World J Gastroenterol 21(15): 4466-4490.

128. Riehl ME (2018) The Emerging Role of Brain-Gut Therapies for Irritable Bowel Syndrome. Gastroenterol Hepatol (NY) 14(7): 436438.

129. Kinsinger SW (2017) Cognitive-behavioral therapy for patients with irritable bowel syndrome: current insights. Psychol Res Behav Manag 10: 231-237.

130. Flik CE, Laan W, Zuithoff NPA, van Rood YR, Smout AJPM, et al. (2019) Efficacy of individual and group hypnotherapy in irritable bowel syndrome (IMAGINE): a multicentre randomised controlled trial Lancet Gastroenterol Hepatol 4(1): 20-31.

131. Hasan SS, Pearson JS, Morris J, Whorwell PJ (2019) Skype Hypnotherapy for Irritable Bowel Syndrome: Effectiveness and Comparison with Face-to-Face Treatment. Int J Clin Exp Hypn 67(1): 69-80.

132. Vasant DH, Whorwell PJ (2019) Gut-focused hypnotherapy for Functional Gastrointestinal Disorders: Evidence-base, practical aspects, and the Manchester Protocol. Neurogastroenterol Motil 31(8): e13573.

133. Lee HH, Choi YY, Choi MG (2014) The Efficacy of Hypnotherapy in the Treatment of Irritable Bowel Syndrome: A Systematic Review and Meta-analysis. J Neurogastroenterol Motil 20(2): 152-162.

134. Peter J, Fournier C, Keip B, Rittershaus N, Stephanou-Rieser N, et al (2018) Intestinal Microbiome in Irritable Bowel Syndrome before and after Gut-Directed Hypnotherapy. Int J Mol Sci 19(11): E3619.

135. Kawanishi H, Sekiguchi A, Funaba M, Fujii Y, Yoshiuchi K, et al (2019) Cognitive behavioral therapy with interoceptive exposure and complementary video materials for irritable bowel syndrome (IBS): protocol for a multicenter randomized controlled trial in Japan. Biopsychosoc Med 13: 14.

136. Lackner JM, Jaccard J, Keefer L, Brenner DM, Firth RS, et al. (2018) Improvement in Gastrointestinal Symptoms After Cognitive Behavior
Therapy for Refractory Irritable Bowel Syndrome. Gastroenterology 155(1): 47-57.

137. Lackner JM, Jaccard J, Radziwon CD, Firth RS, Gudleski GD, et al. (2019) Durability and Decay of Treatment Benefit of Cognitive Behavioral Therapy for Irritable Bowel Syndrome: 12-Month Follow-Up. Am J Gastroenterol 114(2): 330-338.

138. Everitt HA, Landau S, O’Reilly G, Sibelli A, Hughes S, et al. (2019) ACTIB trial group. Assessing telephone-delivered cognitive-behavioural therapy (CBT) and web-delivered CBT versus treatment as usual in irritable bowel syndrome (ACTIB): a multicentre randomised trial. Gut 68(9): 1613-1623.

139. Radu M, Moldovan R, Pintea S, Băban A, Dumitrascu D (2018) Predictors of outcome in cognitive and behavioral interventions for irritable bowel syndrome. A meta-analysis. J Gastrointestin Liver Dis 27(3): 257-263.

140. Zhou C, Zhao E, Li Y, Jia Y, Li F (2019) Exercise therapy of patients with irritable bowel syndrome: A systematic review of randomized controlled trials. Neurogastroenterol Motil 31(2): e13461.

141. Evans S, Seidman LC, Lung K, Sternlieb B, Zeltzer LK (2018) Yoga for Teens with Irritable Bowel Syndrome: Results From a Mixed-Methods Pilot Study. Holist Nurs Pract 32(5): 253-260.

142. Evans S, Lung KC, Seidman LC, Sternlieb B, Zeltzer LK, et al. (2014) Iyengar yoga for adolescents and young adults with irritable bowel syndrome. J Pediatr Gastroenterol Nutr 59(2): 244-253.

143. Patel N, Lacy B (2016) Does Yoga Help Patients with Irritable Bowel Syndrome? Clinical Gastroenterology and Hepatology 14: 1732-1734.

144. Cramer H, Lauche R, Dobos G (2014) Characteristics of randomized controlled trials of yoga: a bibliometric analysis. BMC Complement Altern Med 14: 328.

145. Schumann D, Langhorst J, Dobos G, Cramer H (2018) Randomised clinical trial: yoga vs a low-FODMAP diet in patients with irritable bowel syndrome. Aliment Pharmacol Ther 47(2): 203-211.

146. Reddel S, Putignani L, Del Chierico F (2019) The Impact of LowFODMAPs, Gluten-Free, and Ketogenic Diets on Gut Microbiota Modulation in Pathological Conditions. Nutrients 11(2): E373.

147. Staudacher HM, Ralph FSE, Irving PM, Whelan K, Lomer MCE (2019) Nutrient Intake, Diet Quality, and Diet Diversity in Irritable Bowel Syndrome and the Impact of the Low FODMAP Diet. J Acad Nutr Diet S2212-2672(18)31829-X.

148. Kortlever TL, Ten Bokkel Huinink S, Offereins M, Hebblethwaite C, O'Brien L, et al. (2019) Low-FODMAP Diet Is Associated with Improved Quality of Life in IBS Patients-A Prospective Observational Study. Nutr Clin Pract 34(4): 623-630.

149. Eswaran S, Dolan RD, Ball SC, Jackson K, Chey W (2019) The Impact of a 4-Week Low-FODMAP and mNICE Diet on Nutrient Intake in a Sample of US Adults with Irritable Bowel Syndrome with Diarrhea. J Acad Nutr Diet S2212-2672(18): 31544-2.

150. Mari A, Hosadurg D, Martin L, Zarate-Lopez N, Passananti V, et al. (2019) Adherence with a low-FODMAP diet in irritable bowel syndrome: are eating disorders the missing link? Eur J Gastroenterol Hepatol 31(2): 178-182.

151. Mitchell H, Porter J, Gibson PR, Barrett J, Garg M (2019) Implementation of a diet low in FODMAPs for patients with irritable bowel syndromedirections for future research. Aliment Pharmacol Ther 49(2): 124139.

152. Ooi SL, Correa D, Pak SC (2019) Probiotics, prebiotics, and low FODMAP diet for irritable bowel syndrome - What is the current evidence? Complement Ther Med 43: 73-80.

153. (2008) National Collaborating Centre for Nursing and Supportive Care (UK). Irritable Bowel Syndrome in Adults: Diagnosis and Management of Irritable Bowel Syndrome in Primary Care [Internet]. London: Royal College of Nursing (UK), (NICE Clinical Guidelines 61 (7) Diet and lifestyle. 
154. Jankovich E, S Watkins (2017) “The Low FODMAP Diet Reduced Symptoms in a Patient with Endometriosis and IBS". South African Journal of Clinical Nutrition 30(4): 32-36.
155. El-Salhy M, Ystad SO, Mazzawi T, Gundersen D (2017) Dietary fiber in irritable bowel syndrome (Review). Int J Mol Med 40(3): 607-613. 